This item was submitted to Loughborough's Research Repository by the author.

Items in Figshare are protected by copyright, with all rights reserved, unless otherwise indicated.

\title{
Workability, shear strength and build of wet-process sprayed mortars
}

PLEASE CITE THE PUBLISHED VERSION

PUBLISHER

Thomas Telford / ( ) The Authors

VERSION

AM (Accepted Manuscript)

LICENCE

CC BY-NC-ND 4.0

REPOSITORY RECORD

Austin, Simon A., Peter J. Robins, and Chris I. Goodier. 2019. "Workability, Shear Strength and Build of Wetprocess Sprayed Mortars". figshare. https://hdl.handle.net/2134/4974. 
This item was submitted to Loughborough's Institutional Repository (https://dspace.lboro.ac.uk/) by the author and is made available under the following Creative Commons Licence conditions.

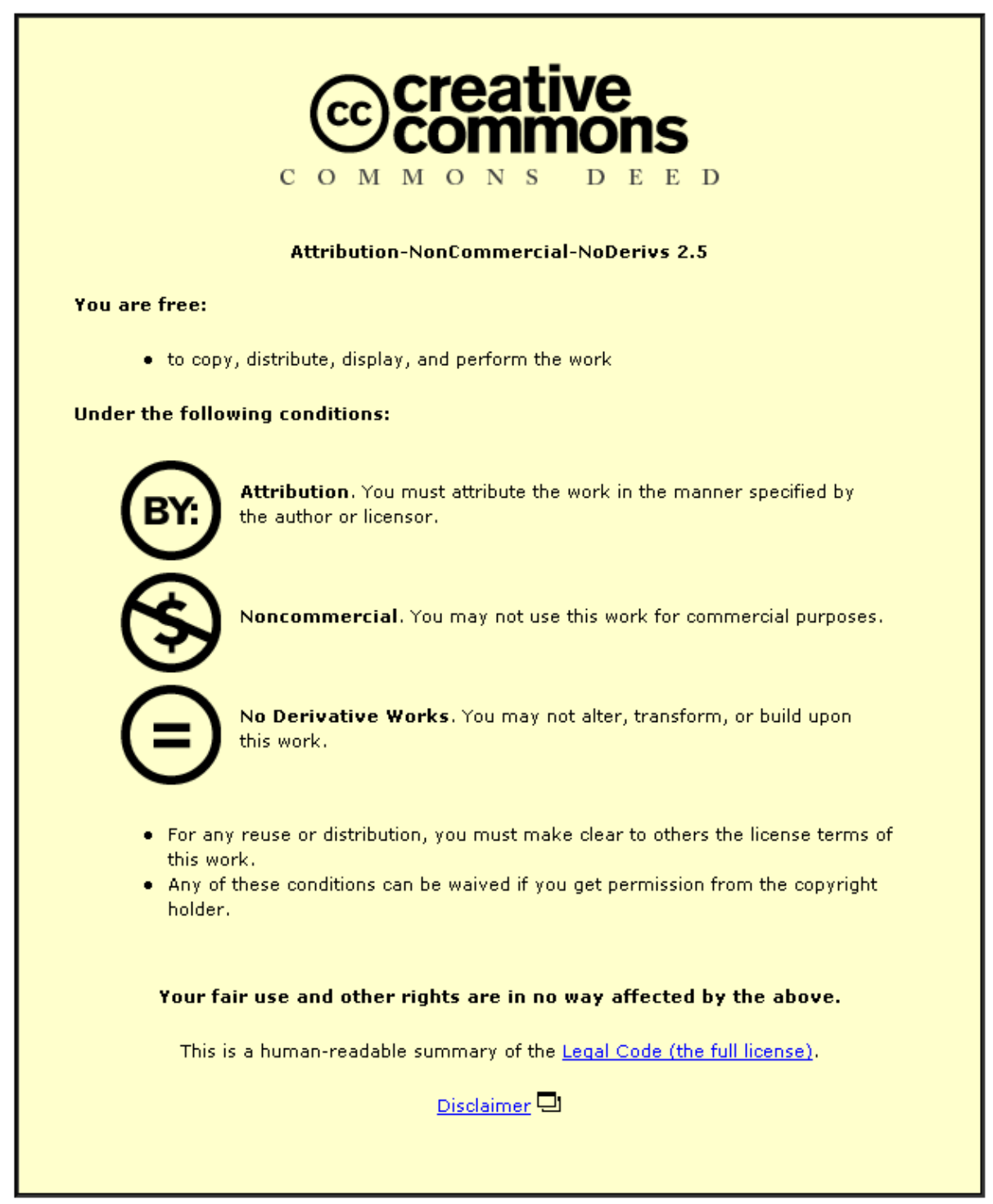

For the full text of this licence, please go to: http://creativecommons.org/licenses/by-nc-nd/2.5/ 
WORKABILITY, SHEAR STRENGTH AND BUILD OF WET-PROCESS SPRAYED MORTARS

Dr S.A.Austin, Dr P.J.Robins and C.I.Goodier.

Department of Civil and Building Engineering,

Loughborough University. 


\begin{abstract}
This paper, which reports on part of a three year research project into wetprocess sprayed concrete for repair, examines the influence of rheology on the pumping and spraying of sprayed mortars. The workability properties of seven commercially available prepackaged repair mortars and six laboratory designed fine mortars were examined using the Tattersall Two-point viscometer, the slump test, a build test and a vane shear strength test. The Two-point apparatus was successful with low-workability mortars and the flow resistance and torque viscosity of the mortars was determined. The vane shear strength test provided an instantaneous reading of the shear strength of the mortars and is compared with their slump. The build value, a measure of sprayability, is then compared with these two workability parameters and the flow resistance in order to determine their inter-relationship.
\end{abstract}

Keywords: Mortars, Rheology, Wet-process, sprayed concrete, Two-point test, Workability, Slump, Build.

Dr S.A.Austin and Dr P.J.Robins are Senior Lecturers in the Department of Civil and Building Engineering at Loughborough University.

C.I.Goodier is a Research Associate in the Department of Civil and Building Engineering at Loughborough University. 


\section{INTRODUCTION}

This paper presents the results from work that is being undertaken as part of a three year research programme at Loughborough University, funded by the Engineering and Physical Science Research Council and supported by substantial industrial collaboration from Balvac Whitley Moran, Fibre Technology, Fosroc International, Gunform International Ltd and Putzmeister UK Ltd. The main aims of this project are:

1. to gain a fundamental understanding of the influence of the pumping/spraying process, mix constituents and proportions on the fresh and hardened properties of wet-mix sprayed concrete;

2. to improve the wet-mix spraying process, in particular operator environment, maximum conveying distances and stop-start flexibility;

3. to specify, measure and optimise in-situ properties, particularly strength, bond and durability;

4. to disseminate information in appropriate form to practising engineers to promote and accelerate the use of wet-mix sprayed concrete for repair in the UK.

The main emphasis of the research project is on mortars and small aggregate concretes $(<10$ $\mathrm{mm}$ ) applied in thin layers $(<100 \mathrm{~mm})$ at controlled low/medium output rates $\left(<5 \mathrm{~m}^{3} / \mathrm{hr}\right)$, in some cases with mesh or fibre reinforcement. This paper concentrates on the fine mortars which contain aggregates with a maximum size of $2-3 \mathrm{~mm}$ and this group has been further divided into pre-packaged proprietary mixes (designated P1 to P7) and designed mixes (D1 to D6). A large range of pre-packaged proprietary mortars have been developed for hand application and there are a number of pre-packaged proprietary mortars being developed specifically for wet spraying. We have been pumping, spraying and testing both the relatively sophisticated pre-packaged materials and the more basic designed mixes in order to characterise their performance and hence identify the constituents and proportions within the mixes that produce sprayable mortars with adequate hardened properties.

\section{RHEOLOGICAL TESTING OF MORTARS}

Recent work conducted by Beaupré ${ }^{1}$ investigated the rheological properties of sprayed concrete and the relationship between pumpability and sprayability, including the development of predictive models based on yield and flow resistance determined from tests conducted with a rotational viscometer. Sprayability can be defined as a property that incorporates parameters such as adhesion (ability of plastic mix to adhere to the surface), cohesion (influencing the thickness that can be built-up), and rebound. Beauprè termed this shootability and found a linear relationship between build-up thickness and the yield value of the mix after spraying, and concluded that shootability increases with flow resistance, and is thus in conflict with pumpability which has the opposite relationship. This research examines further the relationship between build-up thickness, pumpability and shear resistance.

Most authors (Tattersall and Banfill ${ }^{2}$ and Beaupré ${ }^{1}$ ) use the simple Bingham model to express cement paste flow curves as this has been proved to give reasonably accurate and repeatable results within the boundaries of accuracy of the apparatus. For a Bingham fluid the relationship between the shear stress $(\tau)$ and shear rate $(\gamma)$ is given by:

$$
\tau=\tau_{\mathrm{o}}+\mu \cdot \gamma
$$


where $\tau_{\mathrm{o}}$ is the yield stress, above which there is a linear relationship between $\tau$ and $\gamma$ characterised by the plastic viscosity $\mu$. Mortar can be observed to be a shear thinning liquid in which the viscosity decreases when the shear rate increases. It also possesses a yield value: a minimum shear stress that must be applied before the mortar can begin to flow. If this shear thinning effect is permanent then this behaviour is known as irreversible structural breakdown, whereas if the structure reforms after shearing it is said to be thixotropic. This structural breakdown, together with Equation 1 is shown in Figure 1(a).

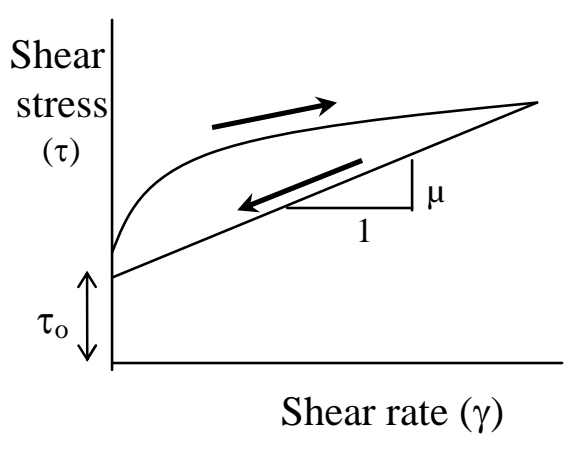

(a)

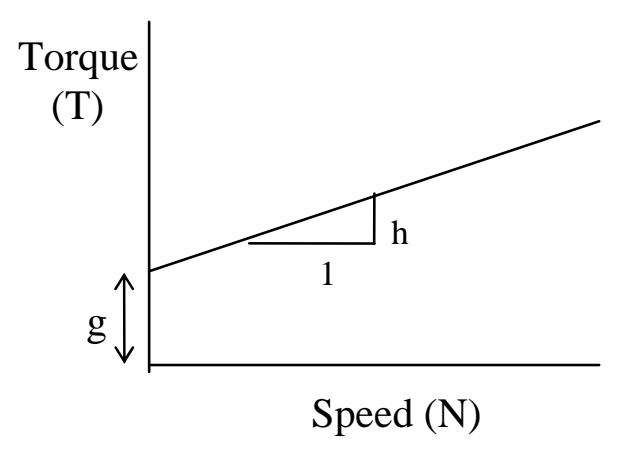

(b)

Figure 1. Typical flow curve for mortars. (a) Stress-strain. (b) Torque-speed.

Tattersall first used a Hobart food mixer to plot flow curves based upon the power needed to drive an impeller in fresh concrete ${ }^{3}$. He later developed a more accurate rheometer with a hydraulic transmission, termed the two-point test apparatus (Mk II). Tattersall found that when the torque $(\mathrm{T})$ was plotted against the speed $(\mathrm{N})$, the relationship was almost linear (Figure 1(b)):

$$
\mathrm{T}=\mathrm{g}+\mathrm{h} . \mathrm{N}
$$

where $g$ is the intercept on the torque axis and $\mathrm{h}$ the slope of the line. Beaupré referred to $\mathrm{g}$ as the flow resistance, and $h$ as the torque viscosity. This equation is of the same form as the Bingham model (Equation 1) and thus it can be said that $\mathrm{g}$ is a measure of yield value, and $\mathrm{h}$ of plastic viscosity. In principle it is possible to convert $g$ and $h$ to fundamental units equivalent to $\tau_{\mathrm{o}}$ and $\mu$ by calibration with standard fluids (Banfill ${ }^{4}$ ) but most investigations work with the direct parameters (which are of course equipment dependent).

\section{MATERIALS AND MORTAR MIXES}

The research has investigated a range of proprietary repair mixes (mainly developed for hand application) and six designed mixes. For the latter, the ordinary Portland cement conformed to BS12:1989 ${ }^{5}$ and the silica fume was a proprietary undensified powder. The sands were a crushed Portland stone sieved to a maximum size of $3 \mathrm{~mm}$ and a building sand graded between $75 \mu \mathrm{mm}$ and $2.36 \mathrm{~mm}$. Some mixes also included an SBR in a 3:1 water:SBR suspension. The proportions of the mixes designed for the project are given in Table 1 and the constituents of the pre-packaged mortars are shown in Table 2. 
The mortars were mixed using a $0.043 \mathrm{~m}^{3}$ capacity forced action paddle mixer. The prepackaged mortars were mixed according to the manufacturers instructions with 3.3 to 4.0 litres of water per $25 \mathrm{Kg}$ bag and a mixing time of approximately 4 minutes. The designed mixes were mixed in the same way and in all cases the water was added until the desired consistency for spraying was achieved. i.e. workable enough to be pumped but stiff enough not to slough after being sprayed onto a vertical substrate. The mortar was pumped through a Putzmeister TS3/EVR variable speed worm pump and then down a $25 \mathrm{~mm}$ diameter rubber hose at an approximate rate of $6 \mathrm{l} / \mathrm{min}$, depending on the mortar. The mortar was then sprayed with an air pressure of approximately $300 \mathrm{kPa}$.

Table 1 Proportions of designed mixes (by weight).

\begin{tabular}{lcccccc}
\hline Mix & $\begin{array}{c}\text { Crushed } \\
\text { stone }\end{array}$ & $\begin{array}{c}\text { Building } \\
\text { sand }\end{array}$ & OPC & $\begin{array}{c}\text { Silica } \\
\text { fume }\end{array}$ & SBR:Water & $\begin{array}{c}\text { Liquid/cement- } \\
\text { itious ratio }\end{array}$ \\
D1 & 3 & 0 & 1 & 0.05 & $1: 3$ & 0.65 \\
D2 & 2 & 1 & 1 & 0.05 & $1: 3$ & 0.55 \\
D3 & 1 & 2 & 1 & 0.05 & $1: 3$ & 0.48 \\
D4 & 0 & 3 & 1 & 0.05 & $1: 3$ & 0.44 \\
D5 & 3 & 0 & 1 & 0.05 & $0: 3$ & -- \\
D6 & 4 & 0 & 1 & 0.05 & $0: 3$ & -- \\
\hline
\end{tabular}

Table 2 Composition of pre-packaged mortars.

\begin{tabular}{|c|c|c|c|c|c|}
\hline Mix & $\begin{array}{l}\text { Polymer } \\
\text { modified }\end{array}$ & Fibres & $\begin{array}{c}\text { Shrinkage } \\
\text { comp. }\end{array}$ & $\begin{array}{l}\text { Lightweight } \\
\text { fillers }\end{array}$ & Mortar description \\
\hline P1 & No & No & Small amount & No & Basic repair mortar \\
\hline $\mathbf{P 2}$ & Yes & Yes & Yes & Yes & High build repair mortar \\
\hline P3 & Yes & Yes & Yes & Yes & 2-part re-profiling mortar \\
\hline P4 & Yes & Yes & No & Yes & Basic repair mortar \\
\hline P5 & Yes & Yes & No & Yes & Render/repair mortar \\
\hline P6 & Yes & Yes & Yes & Some & Repair mortar \\
\hline P7 & Yes & Yes & Yes & Yes & Lightweight repair mortar \\
\hline
\end{tabular}

\section{TESTING PROCEDURE}

The test methods are described briefly below, two for workability, one for pumpability and one for sprayability and, taken in this order, they enable a rheological audit to be made of a mix as it progresses through the mixing, pumping and spraying process.

\section{Workability}

The workability was measured by the slump test ${ }^{6}$ and by a modified form of the shear vane test for soils ${ }^{7}$. Two slumps were measured immediately after the mortar had been mixed and if these slumps were significantly different $(>15 \mathrm{~mm})$ then a third was taken and the average of the two closest values calculated. The shear vane test was investigated as a simple, portable apparatus which could give an indication of the workability of a mortar at various 
points in the pumping and spraying process. It consists of a torque measuring device at the head of the instrument together with a set of enlarged vanes to provide sufficient shear resistance to register on the torque scale. The maximum torque was then used to calculate a shear strength for the mortar (in $\mathrm{kPa}$.).

\section{Pumpability}

The two-point apparatus was the Mk II version developed by Tattersall ${ }^{3}$ which has been found to be satisfactory for medium- to high-workability concretes. The mortars tested here had slumps of between 45 and $80 \mathrm{~mm}$ and it has been suggested that the apparatus might not be sensitive enough for mortars if the torques exerted on the impeller are too low to give a significant increase in pressure, but sufficient change was observed in this work.

During preliminary trials with the apparatus empty it was found that the recorded pressure at a constant speed decreased over time. The apparatus was therefore always warmed up prior to testing for a period of 2 hours at a speed of $0.9 \mathrm{rev} / \mathrm{s}$, after which the change in recorded pressure with time was negligible. The idling pressures were then recorded between the speeds of 0.6 and $2.6 \mathrm{rev} / \mathrm{s}$ at increments of $0.2 \mathrm{rev} / \mathrm{s}$. With the bowl rotating at $0.6 \mathrm{rev} / \mathrm{s}$ the bowl was gradually filled with approximately $25 \mathrm{Kg}$ of mortar to a level $75 \mathrm{~mm}$ below the top of the bowl. The speed was then increased incrementally and the corresponding pressures recorded. Once $2.6 \mathrm{rev} / \mathrm{s}$ had been reached the speed was reduced incrementally in the same way and the corresponding pressures again recorded. The decreasing results that follow the structural breakdown (Figure 1(b)) were used for calculating $g$ and $\mathrm{h}$.

\section{Sprayability}

This was assessed both qualitatively (did the material pass through the nozzle) and quantitatively in terms of the amount of material that could be built up on a standard gritblasted 500x500x50mm concrete substrate. The mortar was sprayed horizontally onto a $300 \times 300 \mathrm{~mm}$ target area to obtain as large an amount of material as possible on the substrate whilst keeping within the 'target'. The mortar would then fail under its own weight either cohesively or adhesively and the total weight of mortar was recorded, together with the failure mode and the maximum depth of build. 
The shear vane provides a basic measure of the shear strength (in $\mathrm{kPa}$ ) of a mortar and this can be plotted against slump (in mm), as shown in Figure 2. The shear strength has been calculated using the British Standard formulas for the measurement of soil shear strength multiplied by a conversion factor for the increased vane size. This shear strength can, in principle, be related to the yield stress $\left(\tau_{0}\right)$ in Equation 1. As expected, the shear strength decreases as the slump increases. It can provide an instantaneous result exactly where the rheological properties of the mortar needs to be measured, i.e. in the hopper of the pump.

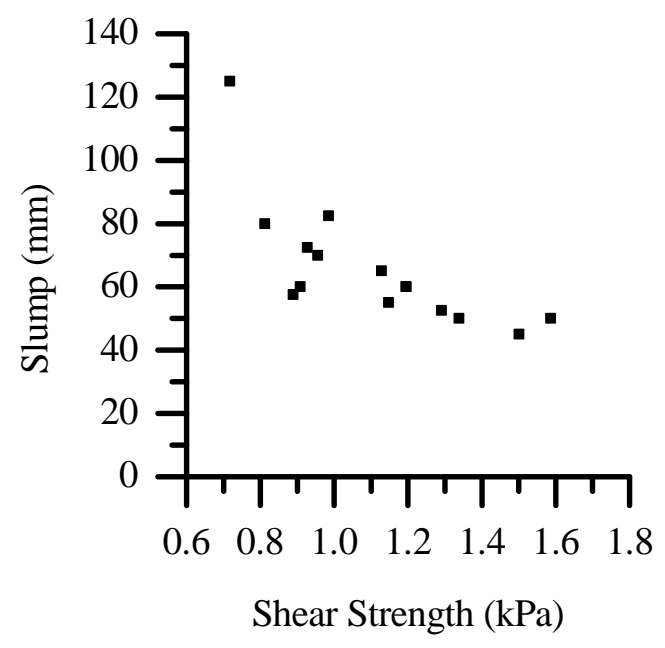

Figure 2. Shear vane Vs slump

\section{Tattersall Two-Point Test}

Figure 3(a) shows the results obtained from the two-point test on the mix P1. The figure shows a distinct up curve and down curve which was typical for all the mortars tested. However, approximately half way along the down curve the torque appears to increase as the impeller speed decreases. This is due to the mortar not falling into the impeller sufficiently and therefore not creating a high enough reading above the idling pressures. A regression line drawn through these points, as shown in Figure 3(a) provides misleading values of $\mathrm{g}$ and $\mathrm{h}$. The points from the initial part of the down curve (Figure 3(b)) have therefore been used in

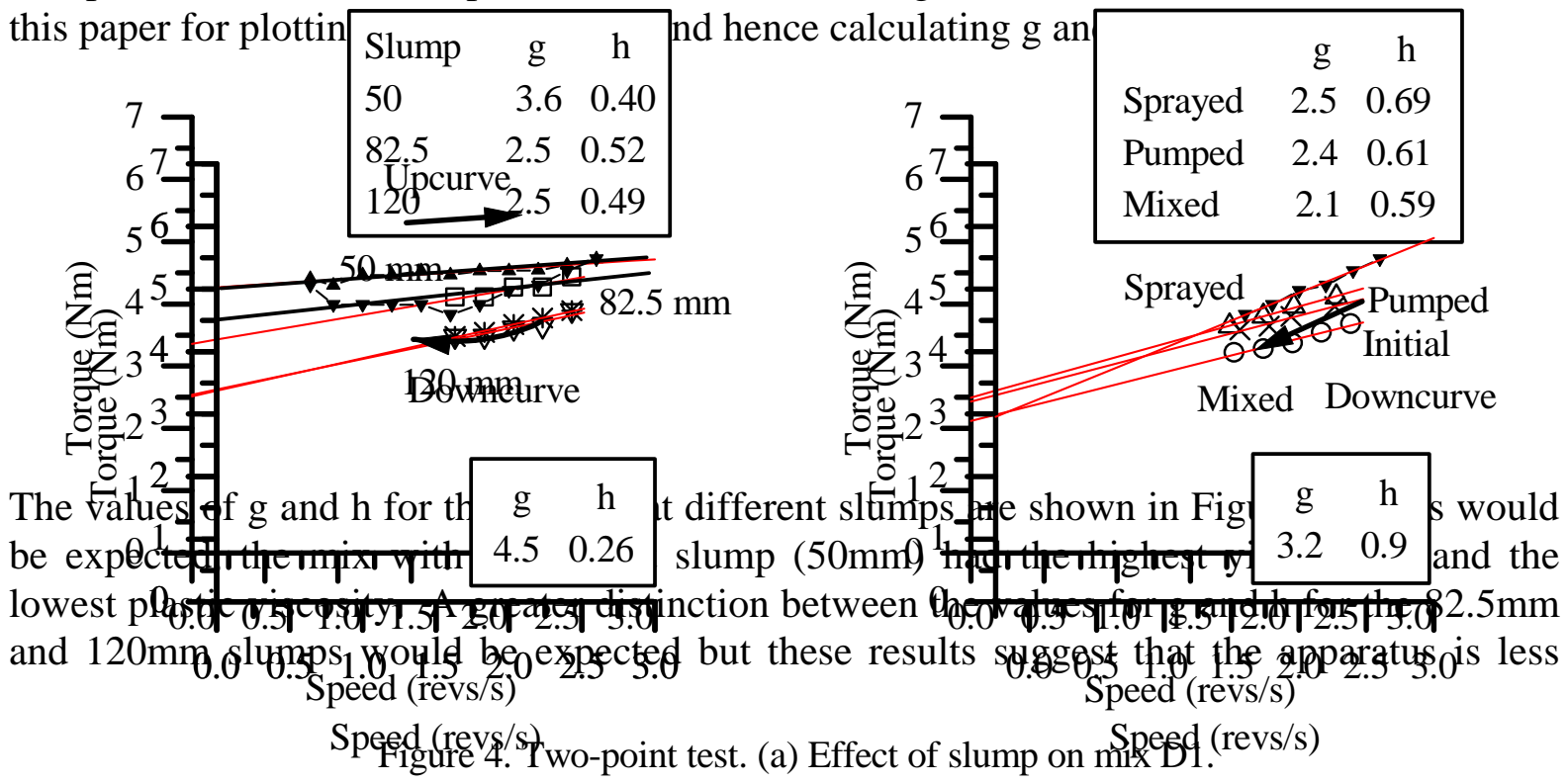

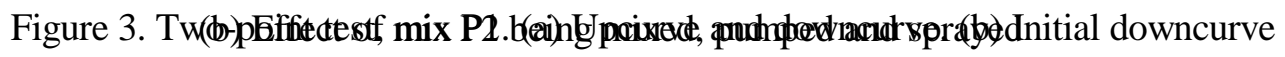


sensitive for mortars at higher slumps. Figure 4(b) shows the $g$ and $\mathrm{h}$ for the mortar P2 after it has been mixed, pumped or sprayed. The increase in both $g$ and $h$ as the mortar is pumped and then sprayed would be expected as the excess air is forced out of the mortar during the pumping and compacting operations.

The two-point test results for all the mortars, both the pre-packaged and the designed mixes, are shown in Figures 5. They were all mixed with water prior to testing until the desired consistency for pumping and spraying had been achieved. Of the pre-packaged mortars, the mortar with both the highest $\mathrm{g}$ and highest $\mathrm{h}$ is mix $\mathrm{P} 1$ which had the most 'basic' mix design of all the pre-packaged mortars tested, and contained no polymers, fibres or lightweight fillers. The mix with the next highest value of g, mix P4, was also known to have a relatively basic mix design. These two mixes were also the cheapest commercially of all the prepackaged mortars tested. The two mixes which were known to be highly polymer-modified (P6 and P3) had the lowest values of g, although their corresponding values of h were very different. The mix P3 is a two-part (powder and liquid) re-profiling mortar which has been formulated to enable it to be applied in thin layers without it separating or being too 'sticky', which could explain why it had the smallest value of g. The designed mixes in Figure 5(b) show a clear trend dependent upon the mix design: the greater the proportion of crushed Portland stone within the mix compared with the building sand then the greater the value of g. The addition of SBR to a mix, in this case mix D5 having no SBR and mix D1 being an identical mix containing a 3:1 water:SBR solution, appears to have little effect on either g or h. This is in contrast with the pre-packaged mortars where the highly polymer-modified mortars possessed a lower value of $\mathrm{g}$.

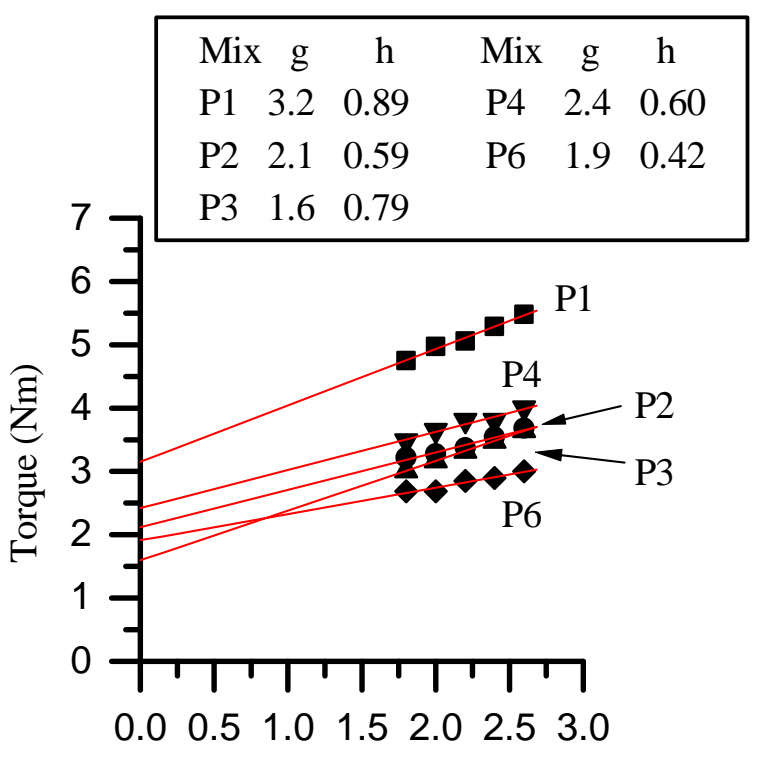

Speed (revs/s)

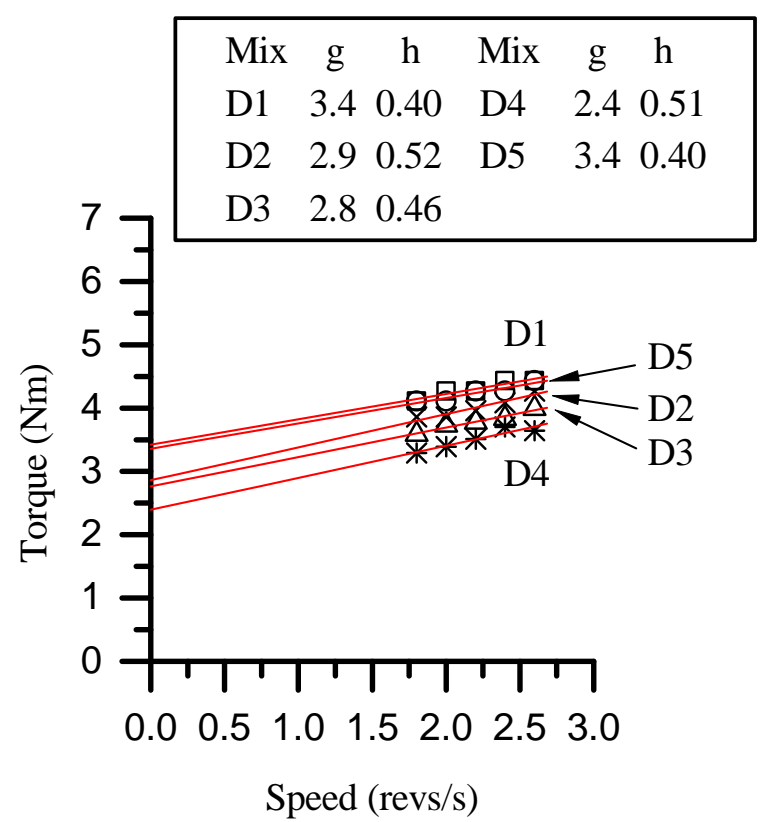

Speed (revs/s)

Figure 5. Two-point test. (a) Pre-packaged mortars. (b) Designed mixes

\section{Build Test}


The build values (in mm) obtained for each of the mixes are shown in Table 3. The mass of the mortar sprayed onto the substrate was also measured and this was used, together with the cross-sectional area of the base of the mortar (usually $300 \mathrm{~mm}$ square) to calculate the maximum shear force produced between the mortar and the substrate. The bending stress was calculated by idealising the mortar on the substrate into the frustum of a square-based pyramid (i.e. a square-based pyramid with the top 'sliced' off parallel with the base). The volume, and therefore the dimensions of this frustum, could be calculated using the mass, the fresh wet density, the area of the base and the height of the frustum (i.e. the build value). This shape was then used to calculate the maximum moment and therefore the maximum bending stress of the mortar.

Table 3. Build test results.

\begin{tabular}{|c|c|c|c|c|c|}
\hline Mix & $\begin{array}{l}\text { Build } \\
\text { (mm) }\end{array}$ & $\begin{array}{l}\text { Mass } \\
\text { (kg) }\end{array}$ & $\begin{array}{c}\text { Max. shear } \\
(\mathrm{N} / \mathrm{m} 2)\end{array}$ & $\begin{array}{c}\text { Bending } \\
\text { stress } \\
(\mathrm{N} / \mathrm{m} 2)\end{array}$ & Failure mode \\
\hline D1 & 210 & 21.4 & 2571 & 2120 & Adhesive \\
\hline D2 & 300 & 27.3 & 3279 & 4922 & Cohesive \\
\hline D3 & 280 & 24.2 & 2907 & 3872 & Adhesive \\
\hline D5 & 270 & 26.8 & 3219 & 3521 & Cohesive \\
\hline D6 & 220 & 23.2 & 2787 & 2357 & Adhesive \\
\hline $\mathbf{P 1}$ & 320 & 41.5 & 3816 & 3476 & Cohesive \\
\hline $\mathbf{P} 2$ & 270 & 13.0 & 3147 & 3002 & Cohesive \\
\hline P3 & 230 & ---- & 2308 & 2375 & \\
\hline P4 & 290 & 26.6 & 3728 & 3662 & Adhesive \\
\hline P5 & 300 & 49.5 & 5946 & 4374 & \\
\hline P6 & 200 & 32.2 & 3868 & 1566 & \\
\hline P7 & 350 & ---- & 2460 & 3853 & \\
\hline
\end{tabular}

Figure 6(a) shows the relationship between the build-up thickness and the slump of the mortar before pumping. This agrees with the results presented previously by Beaupré ${ }^{1}$ who showed that it is not possible to predict the build-value of a mix simply by measuring the slump immediately before pumping. However, the results seem to indicate an increase in build for an increase of slump. This seems the reverse of what would be expected but at the low workabilities tested here, an increase in slump would produce a slightly wetter, and
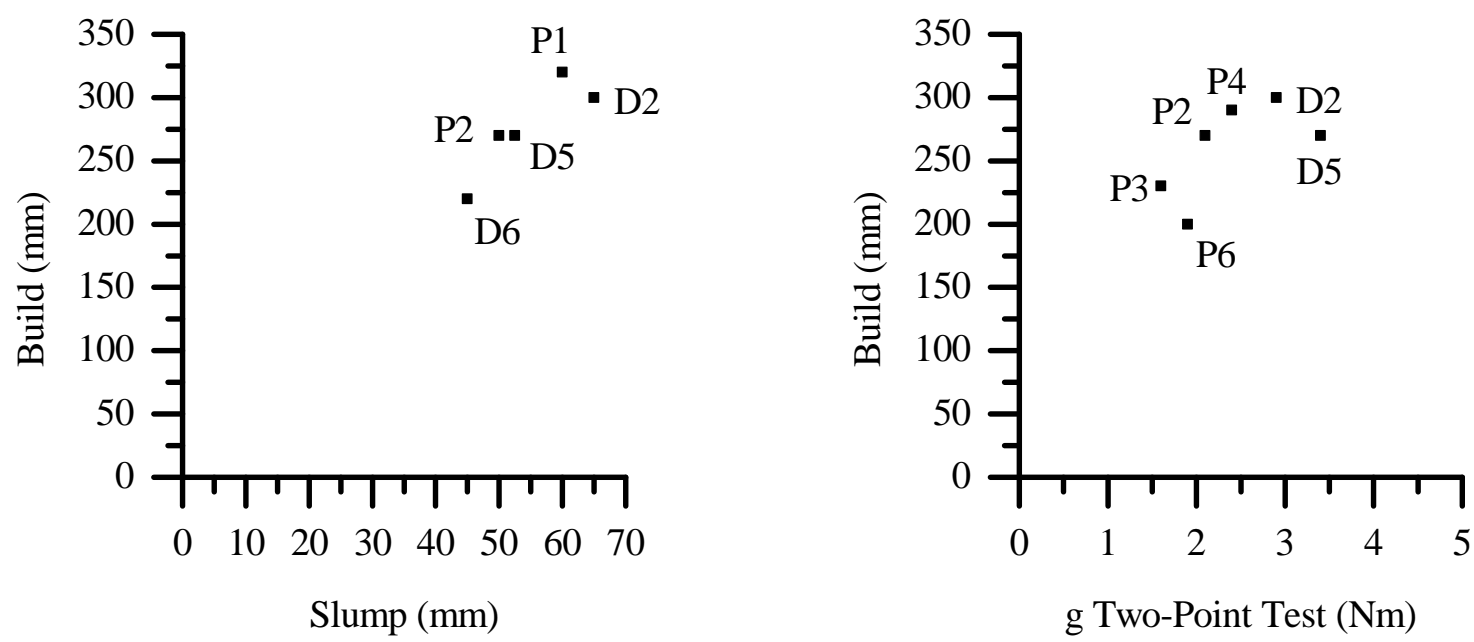

Figure 6. Build value. (a) Slump. (b) g Two-point test 
therefore more cohesive mix, thereby increasing the build.

Beaupré also reported a good relationship between 'g' (the flow resistance, obtained from the Two-point test) and the build value. The relationship between these two parameters in this study are shown in Figure 6(b). The trend is not as strong as that found by Beaupré (who tested $10 \mathrm{~mm}$ aggregate sprayed concretes with build values from 10 to $350 \mathrm{~mm}$ ) compared to the mortars presented here which have build values between 200 and $300 \mathrm{~mm}$. It can be assumed that the line of best fit passes through the origin as a material with zero g (e.g. water) will also have a build-value of zero. It can also be noted that the pre-packaged reprofiling mortar designed to be easily trowelled (P3) had the lowest value of g.

Figure 7 presents the relationship between the build-value and the vane shear strength immediately before pumping. These results indicate an increase in build for a decrease in vane shear strength. As in Figure 6(a), this seems the opposite relationship to what would be expected but at these low workabilities a decrease in shear strength could produce an increase in the cohesiveness of the mortar, and therefore a corresponding increase in build. As the vane shear strength decreases further (due to an increase in workability) a point is reached where the mortar no longer fails due to the tensile stresses being exceeded but by a shear (i.e. flow) failure. At this point the maximum build is obtained. This point is difficult to establish here due to the workabilities of the mixes being within a narrow range. It can be noted that the mix D5 possesses a higher build value than the mix D1(which is identical to the mix D5 except for the addition of SBR), yet approximately the same shear value. The mix P1 also contained no SBR yet possessed the highest build value of all the mixes tested (except for the lightweight mortar, P7(not shown)) which suggests that the presence of a polymer could reduce the build-value for a given shear strength. However, more work would be needed to confirm this hypothesis as it might be expected that polymers would increase the build-value.

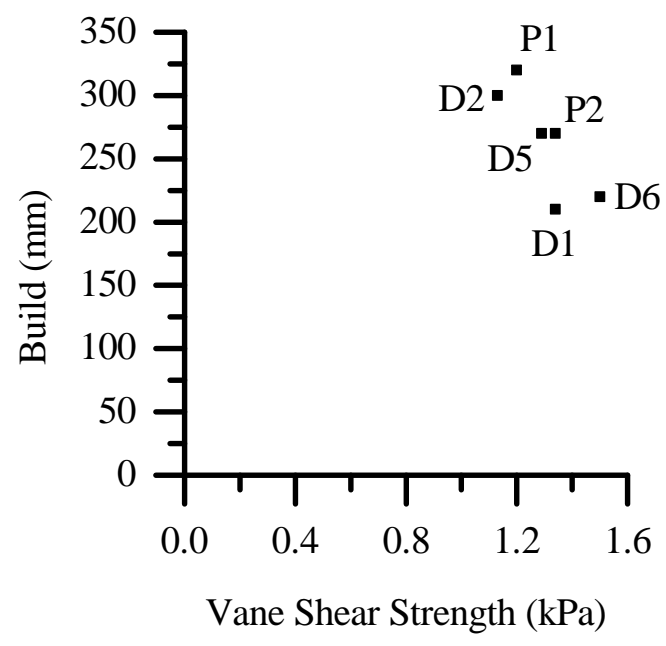

Figure 7. Build value Vs vane shear strength 


\section{CONCLUSIONS}

This paper has presented and discussed a variety of data on the rheological performance of wet-sprayed fine mortars. A rheological audit has been developed and tests for each stage have been used to characterise the pumpability and sprayability of each mortar. A shear vane test has been developed which can give an instantaneous measurement of the shear strength of the mortar where ever this property needs to be assessed. A good correlation with the slump of a mortar has been found and a possible relationship has been presented relating the vane shear strength to the build of the mortar.

The Two-point test apparatus produced satisfactory results with fine mortars with low workabilities, although care needs to be taken in the conduct of the test and interpretation of the results. The grading of the constituents and the presence of polymers both had a significant effect on the results obtained.

\section{ACKNOWLEDGEMENTS}

The authors are grateful for: the financial support of the EPSRC (Grant number GR/K52829); the assistance of the industrial collaborators Balvac Whitley Moran, Fibre Technology, Fosroc International, Gunform International Ltd and Putzmeister UK Ltd; and the supply of additional materials by CMS Pozament, Flexcrete Ltd and Ronacrete Ltd.

\section{REFERENCES}

1. BEAUPRÉ, D. Rheology of high performance shotcrete. PhD Thesis, University of British Colombia, 1994.

2. TATTERSALL, G.H. AND BANFILL P.F.G. The rheology of fresh concrete. Pitman, London, 1983.

3. TATTERSALL, G.H. Workability and Quality Control of Concrete. E\&FN Spon, London, 1991.

4. BANFILL, P.F.G. Rheological methods for assessing the flow properties of mortar and related materials. Construction and Building Materials, 1994, Vol. 8, Number 1, p 43-50.

5. BRITISH STANDARDS INSTITUTION. Specification for Portland cements. BS12:1989, British Standards Institution, London, 1989.

6. BRITISH STANDARDS INSTITUTION SPECIFICATION, Method for determination of slump, BS1881:Part102:1983, British Standards Institution, London, 1983.

7. BRITISH STANDARDS INSTITUTION. Specification for soils for civil engineering purposes, Part 9. In-situ tests, BS 1377:Part 9:1990, British Standards Institution, London, 1990. 